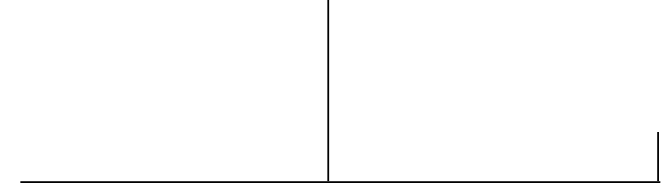

Rev. Latinoam. Psicopat. Fund., São Paulo, v. 11, n. 1, p. 39-54, março 2008

\title{
Consciência da temporalidade e temporalidade da consciência*
}

\author{
Mauro Maldonato
}

\begin{abstract}
A relação tempo-consciência tem sido negligenciada pela pesquisa cientifica. A temporalidade é origem e estrutura da consciência. A experiência temporal não pode ser abordada com clareza apenas pela pesquisa empírica, mas, para que se tente sua compreensão, solicita uma indagação conceitual transdisciplinar. O presente artigo procura traçar um painel das indagações mais relevantes nesse âmbito, a começar pela husserliana reflexão fenomenológica sobre a estrutura e a consciência do tempo, para chegar aos mais recentes estudos empíricos que procuram mapear as áreas e estruturas cerebrais na origem de uma determinada experiência. $O$ estudo, no entanto, mostra a inadequação de descrições meramente instrumentais, e aponta a necessidade de se apreender a natureza da passagem do nivel neurônico para o nivel mental para explicar o fenômeno consciência. É preciso, portanto, investigar os complexos mecanismos de realização da consciência, que têm como fundamento a temporalidade imanente, ofluxo de vida no qual surge a consciência originária do tempo. Para tanto torna-se necessário alcançar um ponto de observação privilegiado, capaz de abarcar conceitualmente as diversas facetas da concretização da consciência; o autor afirma a necessidade de uma pesquisa transdisciplinar que envolva, ao menos, filosofia, psicologia e neurofisiologia.
\end{abstract}

Palavras-chave: Consciência, temporalidade, experiência temporal, fenomenologia da temporalidade

* Tradução de Roberta Barni. 
A fenomenologia tende à verdade, mas a uma verdade em constante movimento; ela antecipa o fato de que toda verdade alcançada é relativa em um horizonte possível e sistemático, e que em todas as direções pré-desenhadas de cumprimento, o que já está atualmente realizado e mais completo é a verdade verdadeira, na qual, no entanto, está incluída, como aproximação, como grau imperfeito, aquela anterior.

Husserl

O sujeito, o qual não pode ser uma série de eventos psíquicos, não pode, no entanto, ser eterno. Resta o fato de que ele é temporal não por algum capricho da constituição humana, mas em virtude de uma necessidade interior. Nós somos convidados a constituirmos do sujeito e do tempo uma concepção de modo tal que eles comunicam do lado de dentro.

Merleau-Ponty

Nos últimos cinqüenta anos, a pesquisa científica tem praticamente negligenciado a questão da relação "tempo-consciência". Dilemas tão antigos quanto a duração da percepção dos objetos no tempo, a unificação temporal dos eventos, a experiência da passagem do tempo e, inversamente, a continuidade do tempo, como muitos outros, continuam sem resposta. Atualmente, junto da comunidade científica, os pontos de vista em discussão são essencialmente dois: 1) aquele dos que vêem a experiência temporal como um enigma de interesse modesto, a ser considerado, na melhor das hipóteses, como um problema empírico; 2) aquele dos que consideram a experiência um autêntico enigma, a ser considerado apenas como uma versão do chamado hard problem da consciência (Chalmers, 1996). Refletindo bem, no entanto, a locução hard problem já constitui, em si, um enigma semântico em relação ao qual nossos recursos conceituais se mostram insuficientes.

A pesquisa experimental, no momento presente, não tem soluções convincentes para o problema da experiência temporal e, em alguns casos, parece mesmo não compreender sua natureza desconcertante. $\mathrm{O}$ enigma da experiência temporal - isto é, a maneira em que o cérebro está na base da experiência consciente - não é uma versão decorrente de uma nova declinação do hard problem da consciência. Trata-se de um enigma diferente daquilo que poderíamos definir, em sentido oposto, como o "problema fácil" da consciência, ou seja, aquele relativo às áreas e às estruturas do cérebro na origem de uma determinada experiência; áreas e estruturas geralmente bem estudadas pelo fMRI 
e pelas técnicas de brain imaging (Posner, 1994) que hoje possibilitam a observação, ao vivo, das partes do cérebro envolvidas numa determinada atividade cognitiva (Picton \& Stuss, 1994).

Apesar disso, muitos indícios levam a crer que a questão da experiência temporal não pode ser abordada com clareza unicamente pela pesquisa empírica, mas sim por uma efetiva e rigorosa interação conceitual entre filósofos, psicólogos e neurocientistas (Varela, 1997a).

Embora seja difícil fazer previsões

... hoje começamos a vislumbrar um novo cenário da ciência, no qual físicos colaborarão com neurofisiologistas, psicólogos com informáticos, matemáticos com biólogos. A personagem do cientista eclético, que hoje é visto como um exemplo raro de genialidade, ou como figura isolada às raias da excentricidade, no futuro se tornará uma incontornável necessidade. (Rota, 1986, p. 10)

$\mathrm{Na}$ medida em que é origem e estrutura da consciência, a temporalidade amarra, como um fio condutor, os diversos planos da reflexão fenomenológica. Nas famosas Lições para uma fenomenologia da consciência interna do tempo (1893-1917), época de estréia da fenomenologia da temporalidade, Husserl levanta severas objeções contra as concepções somatórias e organizacionais da consciência do tempo. Toda forma de conhecimento fundamentada em resultados, fatos, combinação de fatos e de coisas passíveis de serem ordenadas no tempo é totalmente implausível.

A indagação fenomenológica sobre a estrutura e a consciência do tempo deve ser desenvolvida como se se tratasse de determinações a priori, necessárias, lógicas. Há, portanto, uma clara oposição entre a postura cognoscitivofenomenológica e a lógica empírico-experimental. Esta não só se encontra na dificuldade de ter de explicar a origem das estruturas da experiência e do conhecimento, mas também a ordem dos fatos que acontecem no tempo. Aos partidários da abordagem empírica, interessados apenas nas evidências dos fatos psíquicos e totalmente indiferentes ao conhecimento das estruturas atuais do conhecimento, Husserl objeta que uma evidência só existe em sua efetiva vivência, que se renova a todo instante (Masullo, 1995). Uma verdade, de fato, só pode ser apreendida em seu devir, devir que não pode ser um conjunto computável de atos psíquicos, mas temporalidade vivenciada. Nesse sentido, o processo temporal não representa uma parte real do fluxo das experiências, mas uma imanência ideal mediante a qual sempre podemos retornar às evidências adquiridas, antecipando outras, novas, e abrindo um horizonte de potencialidades infinitas (Varela, 1997a).

Percebendo até o fim as dificuldades da psicologia empírica dos meados do século XIX - basta pensar nas pesquisas de autores como Helmholtz, Wundt, Fechner - ao enfrentar a questão do tempo em termos exclusivamente 
quantitativos, Husserl (1965) tenta reverter a situação, respondendo à questão da origem por meio de um caminho lógico, ao abrigo do caráter circunstancial do tempo. Ele questiona o conceito de tempo no próprio ponto de sua origem e constituição, surpreendendo-o ao nascer e suspendendo (epokhé) todas as determinações naturais e empíricas. Na medida em que é manancial primário, o tempo sempre é irrupção de alguma coisa, e não já uma composição.

Em Lições para uma fenomenologia da consciência interna do tempo (1893-1917), Husserl afirma que a consciência se estrutura segundo modalidades temporais, e que seu caráter duplo e incindível unifica os modos de uma consciência se relacionar com outra. Essa atividade de síntese se realiza no fluxo da consciência, na qual cada Erlebnis se desenvolve numa temporalidade própria, articulando-se segundo estruturas comuns a cada momento de consciência (Husserl, 1963). A posição husserliana parece se sustentar na tese de que a consciência é uma unidade em si que é estruturalmente fluxo, não uma unidade ligada a outras unidades. Essa unidade é constitutiva da pluralidade da consciência. Ela revela, ademais, a natureza da seqüência (e dos nexos) entre os instantes reais que faz com que digamos que um determinado evento tem uma duração.

Como se sabe, esse problema levou Husserl a introduzir a noção de retenção: um ponto originário que liga os momentos do fluxo como a duração, o fluir, e assim por diante. Não há nenhuma intenção que não esteja vinculada a uma "segunda intenção" (retenção) que a integra e a torna possível. Isso induz a afirmar que a consciência não é somente consciência, mas fluxo de consciência: não já no sentido de uma consciência interna ao fluxo, mas no sentido de que ela, em sua singularidade, conserva o conteúdo percebido, mesmo quando já não o é. Cada experiência nossa, cada percepção nossa, mesmo a mais simples sensação, é a ressonância da sensação de viver em uma continuidade, não o trânsito de um momento para o outro (Masullo, 2003). Essa seqüência de momentos isolados - desprovida de descontinuidade e que restabelece a impressão de um fluxo se origina na consciência. A experiência do tempo é determinada por uma instantaneidade não apenas intencional, mas também, indissoluvelmente, retencional e tem lugar na consciência (Husserl, 2004).

Que a consciência se dá no tempo e que está sujeita a uma incessante transformação foi coisa que William James compreendeu bem, ele que formulou a brilhante e famosa expressão "stream of consciousness" (1890). A consciência do tempo é, portanto, consciência de um tempo e de um ritmo extremamente mutáveis. Isso implica que tempos cronologicamente iguais podem ser consideravelmente desiguais no plano da vivência (Kimura, 2005). Ao menos em parte, portanto, o fluxo de consciência tem um ritmo natural próprio e endógeno (vivacidade, cansaço, vigília, sono), graus variáveis de clareza, anomalias próprias e específicas, e formas patológicas (sonho, hipnose, alucinações). Se no plano 
neurobiológico a consciência se move no tempo de maneira linear, no plano intencional ela é totalmente desvinculada do "tempo objetivo": o presente, o passado (memória), o futuro (previsões, preocupações, programas). Essa liberdade depende do grau de diferenciação da consciência intencional (Callieri, 2001).

A consciência de alguma coisa - uma multiplicidade, uma relação ou outra coisa qualquer, em que alguma coisa não coesa é percebida como unitária - surge de uma atividade de síntese dos momentos isolados da consciência (Husserl, 1963). Embora essa síntese se refira à vida inteira da consciência e se realize por meio de cada Erlebnisse, ela não está voltada à construção de uma sucessão temporal. Cada experiência isolada é um emergir à consciência (Varela, 1997b; Ramachandran, 2004), já sempre pressuposta como unitária em relação a seus momentos constituintes, os quais não criam a consciência, mas se desenvolvem nela, dando lugar à sua unidade. Esse emergir concerne quer experiências isoladas, quer experiências globais, numa perfeita dinâmica circular (Kelso, 1995). Além das interações locais para o alto, há fenômenos para baixo, que modulam as interações locais com a finalidade de determinar o efeito global da consciência. Esses fenômenos correspondem a processos não-lineares, que participam de um sistema dinâmico de múltiplos níveis, o qual envolve as complexas interações entre cérebro, corpo e ambiente, incluindo-se aí os atos cognoscitivos e conscientes. Nesse sentido, a mente é um modelo espaço-temporal que modula as funções dinâmicas do cérebro (Thompson e Varela, 2001).

Só recentemente os estudiosos de ciências cognitivas começaram a observar com atenção essa co-determinação e suas implicações múltiplas (Maturana e Varela, 1992). Esse problema - que poderia ser definido como temporalidade da mente encarnada - está ligado à redescoberta do papel das emoções. Contra a postura teórico-metodológica das ciências clássicas do comportamento, que eram fortemente cognitivo-cêntricas, os recentes desdobramentos das neurociências mostraram que as emoções estão na base dos processos e das dinâmicas da mente humana (Panksepp, 1998). O neurologista português António Damásio, rompendo com uma tradição que quer a mente bem distinta do corpo, avançou a idéia de que a consciência começa como um sentimento, um tipo peculiar de sentimento, e que consciência e emoções estão estritamente vinculadas, na medida em que a consciência está indissoluvelmente ligada ao sentimento do corpo. Para sustentar essa tese, o estudioso português relata inúmeras evidências que revelam como certos mecanismos cerebrais são comuns tanto às emoções quanto à consciência (Damásio, 1995). Segundo esse esquema, a consciência representa um dispositivo biológico de adaptação ao ambiente fortemente hierárquico, no qual o "Self nuclear" não pode se dar sem o "proto-Self" como, aliás, o "Self autobiográfico" não pode se dar sem o "Self nuclear" (Damásio, 2000). 
Após as famosas pesquisas de Moruzzi e Magoun ${ }^{1}$ sobre o sistema reticular que demonstraram o relevo de oscilações regulares da freqüência e da amplitude do traçado do EEG do estado de sono ao de máxima atenção, ganhou cada vez mais crédito a hipótese de que as funções da consciência seriam subentendidas por estruturas anátomo-funcionais do sistema nervoso central (o sistema límbico, o tálamo, o hipotálamo, a substância reticular e diversas áreas corticais), onde múltiplos inputs sensoriais são integrados para depois serem transformados em experiências conscientes. Nesse espaço de ação global (Baars, 1988) a consciência poderia ser representada como cena teatral iluminada por um refletor cujo feixe de luz permite uma visão apenas parcial do que acontece no palco.

Ora, que na base do fenômeno da consciência haja algum tipo de sincronização entre diferentes regiões cerebrais, e que essa "temporalização" seja um fator decisivo nos processos de integração da informação neural, já parece ser um dado adquirido e compartilhado. Permanece sem resposta, todavia, a pergunta sobre a natureza da passagem do nível neurônico ao mental. Eis porque não basta postular um princípio explicativo (o tempo cronológico ou qualquer outra função sincronizadora) se não explicarmos seus mecanismos de realização (Reichenbach, 1956). Francisco Varela insistiu bastante sobre a necessidade de considerar a consciência como um fenômeno emergente, no qual eventos locais podem dar origem a propriedades ou objetos globais numa causalidade recíproca. Naturalmente, essas invariantes estruturais são incompatíveis com uma representação contínua do tempo linear que herdamos da física clássica (Prigogine, 1986; 1997). As mais recentes teorias das ciências cognitivas sobre a consciência levantam a hipótese de um tempo mínimo necessário para a emersão de eventos naturais que se liguem a um evento cognitivo (Dennet e Kinsbourne, 1992).

Essa estrutura temporal não compactável pode ser analisada como a manifestação de uma integração neural de longo alcance no cérebro, ligada a uma sincronia difusa (...) Esta ligação esclarece a natureza das invariantes fenomenológicas por meio de uma reconstrução dinâmica que está em sua base, fornecendo assim ao processo de sincronização um conteúdo experiencial tangível. (Varela, 1997a, p. 32)

O fenômeno da consciência é dado pela atividade integrada e, concomitantemente, altamente diferenciada do cérebro. A hipótese emergentista representa uma alternativa crível à teoria que identifica a consciência com diferentes esta-

1. Giuseppe Moruzzi e Horace Magoun descobriram, em 1949, na Northwestern University de Chicago, o ARAS - Ascending Reticular Activating System ou "Sistema Reticular Ativador Ascendente", formação do Sistema Nervoso Central de importância capital para a neurobiologia. 
dos funcionais do cérebro. É plausível supor que essas atividades emirjam exclusivamente em altos níveis de complexidade, muito além de determinados patamares e em presença de ondas de sincronização dotadas de freqüências específicas (40 Hz). Para Francis Crick e Christof Koch (1992), esses patamares poderiam representar os correlatos eletrofisiológicos do surgimento dos estados de consciência.

Naturalmente, a consciência não é apenas isso. Ela excede, mesmo sem nunca abandoná-las, as raias do sistema nervoso e do corpo para se aproximar da experiência individual, que está relacionada às irrepetíveis e contingentes condições sociais e culturais em que o sujeito se insere. Estendendo a brilhante (e intelectualmente provocadora) locução de Varela "a consciência não está na cabeça", poderíamos dizer que a mente afetiva não está na cabeça, mas no corpo inteiro. Além disso, que os estados afetivo-temporais emergem de uma recíproca co-determinação e co-implicação entre mente e corpo. Difícil, nessa altura, não pensar na idéia de "paticidade", de Victor Von Weizsäecker (1951), na qual o termo indica nem tanto uma possibilidade ou a idealização de uma condição de possibilidade, mas o tempo como fenômeno: fenômeno - ao mesmo tempo semântico e "pático" - que é uma experiência e não uma medida da mudança. $\mathrm{O}$ tempo, portanto, não é um medidor aritmético, mas temporalidade encarnada, mente encarnada, corporeidade vivenciada (Merleau-Ponty, 1942; 1964).

A relação da consciência com sua temporalidade é extremamente complexa, e não admite uma descrição instrumental, segundo uma leitura redutiva da fórmula anima utens corpore. Nem pode ser aceita a fórmula antropológica segundo a qual "o homem é o seu corpo". A consciência é mais do que seu corpo que, ao viver continuamente, transcende. Esse transcender não implica algum dualismo de mente e corpo, mas uma intensa experiência unitária. Em toda decisão, atividade ou determinação da experiência, essa unidade nunca é questionada (Putnam, 1985). Essa consciência encarnada tem como "correlato" a própria temporalidade. Os Erlebnisse são ordenados temporalmente com um início e um fim, e, todavia, sempre no horizonte infinito do tempo imanente. A experiência da consciência do tempo se revela dotada de uma intencionalidade determinada pelo sentido que cada Erlebnisse imprime nos próprios objetos. Seu fundamento, portanto, é temporalidade imanente, o fluxo de vida que se constitui em si e por si, no qual se articula a consciência originária do tempo (Husserl, 1981). Os Erlebnisse que compõem o fluxo da temporalidade nascem da consciência originária do tempo, isto é, daquela consciência, já sempre pressuposta, que assume a forma das objetividades do mundo.

Essa temporalidade imanente pressupõe, como observamos anteriormente, a universal consciência interna do tempo: que não é sintética e, portanto, temporal; nem sintética e, ao mesmo tempo, temporal; mas sintética porque 
temporal (Husserl, 1963). Essa atividade sintética representa uma realidade primária - a consciência - que se dá nas formas e nos modos da temporalidade. Nesse sentido, precisamente na medida em que é temporal, a consciência sempre é pressuposta, já que seu proceder deriva naturaliter precisamente da vivência temporalmente estruturada.

A consciência é plenamente orientada para o exterior. Seus conteúdos são determinados em máxima parte pelo exterior. Isso confirma a autonomia da consciência. Seja qual for seu conteúdo, ele entra em certa disposição da consciência, em certo estado de humor, em certa constelação de tendências, em certo grau de clareza e de vigilância da consciência (Callieri, 1987). Esse conteúdo se torna capaz de existir e agir apenas na totalidade da consciência. Isso não vale somente para o instante em que acontece o ingresso na consciência, mas também para todo o destino seguinte dos conteúdos ingressantes na consciência. Nunca, nem sequer no âmbito mais restrito do próprio campo perceptivo, a consciência é apenas receptiva. As funções integrativas seguem suas leis gerais, sua marca individual, o próprio destino individual, conforme a própria situação global, já sempre pressuposta, embora dada a cada vez. Também as imagens do mundo e do ambiente - mesmo ali onde há igualdade objetiva de ambiente (ou quase) - são consideravelmente diferentes de espécie a espécie e também diferem, dentro da mesma espécie, de indivíduo a indivíduo (Gibson, 1966).

Nos parágrafos 10 e 11 das Lições, Husserl efetua uma distinção entre uma consciência interior, intencionalmente voltada para o objeto transcendente, e uma consciência exterior (voltada para a duração de um evento exterior). Uma fenomenologia da consciência interior do tempo, portanto, deve ser considerada em sua dimensão reflexiva, que bebe da própria nascente do processo de intencionalidade. Mas na medida em que é intencionalidade, o conceito do tempo é, inevitavelmente, um conceito relacional. Essa consciência da relação - que poderia ser definida em plano neurobiológico como "consciência estendida", isto é, um nível de consciência que se constitui a partir da consciência nuclear está na origem do "Self autobiográfico" (Damásio, 1995). Esse nível de consciência tem como condição de possibilidade a linguagem, pois apenas a linguagem permite formular nossa história pessoal, na qual tomam lugar as lembranças, as expectativas, as esperanças e, mais geralmente, os sentimentos direcionados (Lersch, 1942). Fora dessa relação, tudo parece inapreensível. Esse caráter relacional tem a ver, para usarmos um termo caro à psicanálise, com o Un-heimlich, a experiência do estranho, com o outro que se torna imagem como presença secundária: não mais no sentido de não-presente, mas no sentido de uma "a-presentação" (Husserl, 2002) que indica a intencionalidade de uma copresença e de um con-texto, mesmo diante da falta de uma a-presentação original de sua vida psíquica. 
Se eu apreender um corpo externo, parecido com meu corpo orgânico, esse corpo, por meio dessa semelhança, exerce a função de uma apresentação na forma da "expressão". Faz parte disso que contextualmente seja colocada uma interioridade múltipla que se desenvolve de maneira típica, que por sua vez requer uma exterioridade correspondente, a qual realmente se suceda de maneira a corresponder às expectativas. Onde a interpretação tem êxito e se confirma nessa maneira de proceder, a apresentação se conserva por hábito. Eventualmente em nosso ambiente produzimos eventos que conforme a direção da empatia têm de manifestar-se de maneiras correspondentes de aparecimento também no ambiente interno do estranho e portanto têm de resultar, conforme a analogia, motivos para o comportamento do outro, que têm de expressar-se tanto em sua corporeidade, quanto nas outras expressões, em suas ações, nas expressões fônicas. (Husserl, 1973, p. 249)

A experiência da subjetividade estranha é comum ao Eu e ao outro. Só na medida em que é originariamente co-incidente com um indivíduo corpóreo do mundo, o outro pode ser identificado como sujeito-para-o-mundo. Por outro lado, se o mundo objetivo vive da harmonia entre os indivíduos de uma comunidade normal, também a identificação das recíprocas vivências viverá da ordem espontânea recíproca que possibilita o entendimento intersubjetivo (Maturana e Varela, 1985). A esfera originária à qual a constituição da alteridade diz inteiramente respeito não é um dado fenomenologicamente primário, mas uma "abstração" com relação ao conteúdo concreto da experiência subjetiva primária (Husserl, 1973).

Husserl nega que o outro possa se-dar-em-si. Nega, outrossim, o sentido original da experiência do estranho, isto é, o scandalon pelo qual ela transcende a minha intencionalidade, rompendo os esquemas consolidados no proceder temporal-sintético de minha consciência (Lévinas, 2002). Husserl parece desinteressado do irromper de um imprevisivelmente outro na esfera do Eu. Ele, de fato, reduz essa irrupção em uma co-presença secundária que se origina na própria esfera de pertencimento do Eu. O problema, então, é conseguir resolver essa irrupção, compreender a passagem por meio da qual alguma coisa irrompe, e cuja falta torna todo o resto impensável. Claro, há uma forte diferença de significado entre a noção de estranho e a de outro. Enquanto o primeiro se configura como não-Eu, isto é, que não implica em si em presença do Eu, senão (e negativamente) no plano terminológico, o segundo pode ser definido a partir de uma diferenciação do sentido no fundamento do ser-próprio, na força do qual o não-eu se torna um outro-Eu.

Entretanto, de onde o Eu deriva a certeza da presença da realidade psíquica no corpo alheio? De novas "apresentações" concordantes, embora essa concordância seja subvertida pela intemporalidade que o estranho sempre representa para a consciência do Eu. Justamente essa intemporalidade torna 
inalcançável o estranho em sua originalidade; mais um motivo para admitir-se que a temporalidade implica uma diferença, uma descontinuidade, um contragolpe, que nada mais são do que formas diferentes da alteridade (Bernet, 1994). Diante da cifra ambígua dessa alteridade há que perguntar-se: o tempo é o horizonte originário que precede e se erige sobre cada manifestação da alteridade ou, viceversa, a manifestação do outro é o que con-fere sentido ao tempo?

$\mathrm{O}$ corpo de que tenho experiência se manifesta perfeitamente estranho na mutabilidade de seu comportamento exterior. O modo de ser do estranho se fundamenta nesse processo em que o originariamente inderivável é alcançado por sucessivas aproximações (Merleau-Ponty, 1979).

Isso, todavia, não significa que podemos conhecer o estranho em sua originalidade, e sim que dele podemos nos aproximar "a-perceptivamente". Nesse sentido, se o enigma do outro-Eu é dissolvido, não podemos dizer o mesmo quanto ao enigma do estranho, do não-Eu com que o problema da temporalidade coincide (Anzieu, 1992).

Na Quinta meditação (1963), Husserl vai estreitando, até eliminá-la, a diferença entre estranho e alter ego, que se torna assim diferença apenas nominal, mas não de sentido. Uma vez que cai essa distinção conceitual entre estranho e outro, cujo ápice sutil estava no conceito de temporalidade estranha, a relação ego/alter ego encontra, na temporalidade, seu ponto íntimo de ligação. É no limite entre passado e presente que se desdobra a conexão entre a experiência de si que se dá unitariamente e sem fraturas do $\mathrm{Eu}-\mathrm{e}$ a presença do estranho. Este processo se renova simetricamente na esfera primária do outro com relação à experiência que ele tem da minha. A consciência de termos em comum é pertença de um único mundo (Böckenhoff, 1970) e passa pelas tramas das diferentes temporalidades egóicas e alter-egóicas, cada qual sendo uma maneira original e subjetivo-individual de aparecimento da temporalidade objetiva. A experiência do estranho não testemunha mais a diacronia originária entre Eu e não-Eu, pois se transformou numa espécie de empatia em que a própria tensão entre Eu e nãoEu se abranda (Varela, 1985; Thompson, 2001).

Essa declinação da consciência tem as características de uma experiência duradoura, de um modo de nossa vida vivenciada ou, melhor, de nosso corpo vivenciado. Nessa sintonia entre corpo e mundo, do sono à vigília, reside a função tética da consciência. Essa propensão ordenadora é conforme aos princípios de uma ação voluntária. Estudos recentes designam um papel proeminente às interações neurais que precedem e preparam uma ação voluntária (Jeannerod, 1997) que é, sobretudo, uma experiência arraigada na percepção do corpo como corpo vivenciado (Merleau-Ponty, 1945) e na interdependência entre o corpo vivido e seu mundo. Aqui uma análise fenomenológica da ação voluntária e da percepção do corpo mostra todas as suas extraordinárias potencialidades. 
A fenomenologia da atualidade vivenciada repousa na noção de "campo", isto é, numa totalidade organizada e limitada. Para a experiência vivida, isso responde à necessidade de se circunscrever em seu significado, em suas dimensões, como uma estrutura momentânea, transitória e sincrônica. Recuperando de Bergson o conceito de organização, de Husserl o de intencionalidade da Gestaltpsychologie, a organização do "campo perceptivo" e a "noção de unidade composta", é possível recuperar o conceito de Henri Ey de "estrutura fundamental do campo da consciência". Hoje, esse conceito nos permite alargar o "horizonte" de modo realmente considerável, o que satisfaz plenamente as exigências neurofenomenológicas (Varela, 1996) de compreensão da consciência. Aqui, o campo da consciência tem uma genealogia, uma estratificação, um fundo (Untergrund), que se volta para o outro dinamicamente, conforme uma determinada ordenação. Essa consciência constituída restitui forma à relação do Eu com o seu mundo.

Essas noções - que se articulam na possibilidade de abrir-se para o mundo e nele orientar-se, ao projetar o espaço vivenciado em direção ao mundo dos objetos, e ao deter e estender o tempo - revelam-se úteis em âmbito clínico para a classificação dos distúrbios da consciência, nos quais o plano neurofisiológico se conjuga com o da experiência vivida, favorecendo o confronto entre a descrição subjetiva e a observação objetiva do clínico.

Apesar disso, explicitando-se histórica, axiológica e verbalmente, a consciência permanece em si mesma (e para si mesma) uma questão muito controvertida (De Waelhens, 1961). Basta pensar no tema do campo de consciência, em que este se constitui a partir de uma proto-experiência que nasce da tensão extrema entre o motus e o objeto: tensão na qual a consciência desdobra seu poder ordenador, abrindo-se ao mundo. Nesse campo de presença, instintos, pulsões e emoções são integrados numa "estrutura temporal" que exige a "presença" do sujeito. Em condições normais, a consciência se torna constituinte, transformando, o tempo todo, a perspectiva em favor de uma estrutura "facultativa" e uma "disponibilidade" que são propriedade do sujeito e supõem dinâmicas verticais de campo (Maldonato, 2004). Nesse sentido é possível falar de um nível normal de vigilância, isto é, de um estado de clareza entre o sono e a hiper-vigília que favorece a possibilidade, especificamente humana, de entabular um diálogo consigo mesmo, perfeitamente consciente da própria condição normal e patológica. É desse modo que a estrutura da consciência pode ter acesso à autonomia de sua organização e se tornar o "modo" de nosso "corpo vivenciado" (Straus, 1956).

Naturalmente, estar consciente não deve ser confundido com o campo de consciência. Embora haja fortes ligações, estar consciente excede largamente o campo de consciência. A idéia de emergência faz do Eu não mais um espectador 
passivo do Teatro Cartesiano em que tudo converge (Dennett, 1991), mas sim o ator de uma "presença de campo" que, numa dinâmica vertical, segue e permeia os diversos graus constitutivos da consciência até o ordenamento mais elevado do campo da presença. Nestes termos, a consciência não pode ser representada como o ponto terminal de um fluxo linear de processos que se seguem de modo ordenado ou seqüencial. Mais convincente é a hipótese de uma multiplicidade de circuitos, em estrita interconexão entre si, que realizam a unidade consciente, e não relatando a atividade dos diversos módulos do córtex cerebral (que age como coletor), mas funcionando de maneira estritamente integrada e interdependente.

O papel crucial dos processos neurofisiológicos não enfraquece a contínua remissão do sujeito à sua alteridade. As reflexões de Zutt (1952) e de Ey (1963) nos parecem, aqui, extremamente atuais. Para compreender a fundo a consciência, de fato, são igualmente importantes ambos os aspectos da vida da consciência: a própria história de vida no mundo (as posições, as avaliações, as escolhas do indivíduo consigo e com os outros) e o atual (a experiência do momento). Aqui, encontra plena justificação aquela pluralidade metodológica que circunscreve os tão disseminados quanto infecundos extremismos naturalísticos, metapsicológicos e mais.

\section{Referências}

BaArs, B. J. A cognitive theory of consciousness. Cambridge/London: Cambridge University Press, 1988.

Block, R. A. (org.). Cognitive models of psychological time. Hillsdale: Lawrence Erlbaum Associates, 1990.

Byrne, A. The Emergent Mind. 1993. Ph.D. Dissertation, Princeton University.

Callieri, B. Quando vince l'ombra. Problemi di psicopatologia clinica. Saggio introduttivo di Mauro Maldonato. Roma: Edizioni Universitarie Romane, 2001.

Chalmers, D.J. The Conscious Mind: in Search of a Fundamental Theory. New York: Oxford University Press, 1996.

Crick, F. The Astonishing Hypothesis: The Scientific Search for the Soul. New York: Charles Scribner's Sons, 1994.

Crick, F., Косн, C. The problem of consciousness. Scientific American, set. 1992.

Damásıo, A. L'errore di Cartesio. Milano: Adelphi, 1995.

. Emozione e coscienza. Milano: Adelphi, 2000.

De Waelhens, A. La philosophie e les expériences naturelles. La Haye: Martinus Nijhoff, 1961. 
Dennet, D.; Kinsbourne, M. Time and the observer: the when of consciousness in the brain. Behavioral and brain science, Cambridge, n. 15, 1992.

Edelman, G. The Remembered Present: A Biological Theory of Consciousness. New York: Basic Books, 1989.

Gibson, J. J. The problem of temporal order in stimulation and perception. Journal of Psychology, n. 62, 1966.

Gurwitshc, A. Husserl's theory of the intentionality of counsciousness. In: Dreyfus, H. (org.). Husserl, Intentionality and Cognitive Science. Cambridge/London: Mit Press, 1982. p. 59-71.

Husserl, E. (1963). Meditazioni cartesiane con l'aggiunta dei discorsi parigini. Milano: Bompiani, 1989.

Einaudi, 1965.

. Idee per una fenomenologia pura e per una filosofia fenomenologica. Torino: . Zur Phänomenologie des Inneren Zeitbewußtseins (1893-1917). In: Husserliana. Den Haag: Bd.X, Nijhoff, 1966.

. Zur Phänomenologie der Intersubjektivität. Texte aus dem Nachlass. (Sulla fenomenologia dell'intersoggettività. Testi dal lascito). Zweier Teil: 1921-1928. Den Haag: Nijhoff, 1973.

. Per la fenomenologia della coscienza interna del tempo (1893-1917). 4. ed. Milano: Franco Angeli, 2004.

. Lições para uma fenomenologia da consciência interna do tempo. Lisboa: Imprensa Nacional Casa da Moeda, 1994.

JAMES, W. The Principles of Psychology. London: MacMillan, 1890.

Jeannerod, M. Cognitive Neuroscience of Action. Oxford: Blackwell, 1997.

Kelso, J. A. S. Dynamic Patterns: The Self-Organization of Brain and Behavior. Cambridge: The Mit Press, 1995.

Kimura, B. Scritti di psicopatologia fenomenologia. Roma: Giovanni Fioriti, 2005.

Lersch, P. Il carattere. I sentimenti, le tendenze, la volontà. Padova: CEDAM, 1942.

LÉvinas, E. Dall'altro all'io. Roma: Meltemi, 2002.

Maldonato, M. Na linha do mistério: Consciência de si e Consciência do mundo. Mente \& Cérebro, nov. 2004, p. 75-81.

Masullo, A. Il tempo e la grazia. Roma: Donzelli, 1995.

$2 \overline{003 .}$ . Lezioni sull'intersoggettività. Ficthe e Husserl. Napoli: Editoriale Scientifica,

Maturana, H.; Varela, F. L'albero della conoscienza. Milano: Garzanti, 1985. 
Merleau-Ponty, M. (1942). La struttura del comportamento. Milano: Bompiani, 1963. . (1945). Fenomenologia della percezione. Milano: Il Saggiatore, 1965. . (1964). Il visibile e l'invisibile. Milano: Bompiani, 1993.

Panksepp, J. Affective Neuroscience. The Foundations of Human and Animal Emotions. New York: Oxford University Press, 1998.

Petitot, J.; Varela, F. J.; Pachoud, B.; Roy, J.-M. (Orgs.). Naturalizing Phenomenology: Issues in Contemporary Phenomenology and Cognitive Science. Stanford: Stanford University Press, 1999.

Picton, T.; Stuss, D. Neurobiology of conscious experience. Current Biology, n. 4, 1994. Posner, M. I. Attention: the mechanisms of consciousness. Proceedings of the National Academy of Sciences of USA, n. 91, p. 7398-7403, 1994.

Prigogine, I. Dall'essere al divenire. Tempo e complessità nelle scienze físiche. Torino: Einaudi, 1986.

Ramachandran, V. The emerging mind. London: Profile Books, 2004.

Reichendach, H. The direction of time. Berkeley: University of California Press, 1956.

Rota, G. C. Osservazioni sull'intelligenza artificiale. Bollettino dell'Unione Matematica Italiana, serie 6, v. 5-a, 1986.

SeArle, J., Intentionality. An Essay in the Philosophy of Mind. Cambridge: CUP, 1983.

Straus, E. Vom Sinn der Sinne. Berlin: Springer, 1956.

Thompson, E. Empathy and consciousness. Journal of Consciousness Studies, v. 8, n. 5-7, p. 1-32, 2001.

Thompson, E.; Varela, F. J. Radical embodiment: neural dynamics and consciousness. Trends in Cognitive Sciences, n. 5, p. 418-425, 2001.

VArela, F. J. Complessità del vivente e autonomia del cervello. In: Bocchi G.; Ceruti M. (orgs.). La sfida della complessità. Milano: Feltrinelli, 1985.

. Neurofenomenologia: una soluzione metodologica al problema difficile. Pluriverso, ano II, n. 3, p. 16-39, nov. 1997a.

. (Org.). Sleeping, Dreaming, and Dying: An Exploration of Consciousness with the Dalai Lama. Boston: Wisdom Publications, 1997b.

Varela, F.; Thompson, E., Rosch, E. The Embodied Mind: Cognitive Science and Human Experience. Cambridge: The MIT Press, 1991.

VArela, F. et al. The brainweb: phase synchronization and large-scale integration. Nature Reviews Neuroscience, n. 2, p. 229-239, 2001.

WeIzSÄECKER, V. von. Der kranke Mensch. Stuttgart: Koehler, 1951. 
Zutт, J. Der ästhetische Erlebnisbereich und seine Krankhaften Abwandlungen. Nervenarzt, n. 23, p. 163, 1952.

\section{Resumos}

(Conciencia de la temporalidad e temporalidad de la conciencia)

La investigación científica ha descuidado la relación tiempo-conciencia. La temporalidad es origen y estructura de la conciencia. La experiencia temporal no puede ser abordada con claridad con el único instrumento de la investigación empírica. Para intentar comprenderla, se solicita una indagación conceptual interdisciplinaria. El presente artículo busca trazar un panel de las indagaciones más relevantes en ese ámbito, comenzando por la reflexión fenomenológica husserliana sobre la estructura y la conciencia del tiempo, para llegar a los más recientes estudios empíricos que buscan mapear las áreas y las estructuras cerebrales en el origen de una determinada experiencia. Entre tanto, el estudio indica la inadecuación de descripciones meramente instrumentales y señala la necesidad de aprehender la naturaleza del pasaje del nivel neuronal para el nivel mental para explicar el fenómeno de la conciencia. Es preciso, para esto, investigar los complejos mecanismos de realización de la conciencia, que tienen como fundamento la temporalidad inmanente, el flujo de vida en el cual surge la conciencia originaria del tiempo. Para eso, se hace necesario alcanzar un punto de observación privilegiado, capaz de conceptualmente abarcar las variadas facetas de la concretización de la conciencia; el autor afirma la necesidad de una investigación interdisciplinaria, englobando por lo menos, filosofía, psicología y neurofisiología.

Palabras clave: Conciencia, temporalidad, experiencia temporal, fenomenología de la temporalidad

(Conscience de la temporalité et temporalité de la conscience)

La recherche scientifique néglige le rapport temps-conscience. La temporalité est origine et structure de la conscience. La seule recherche empirique ne permet pas d'envisager avec clarté l'expérience temporelle, dont la compréhension demande une approche conceptuelle transdisciplinaire. Le présent article dresse un panorama des questionnements les plus importants dans ce domaine, à commencer par la réflexion husserlienne phénoménologique sur la structure et la conscience du temps, pour en arriver aux études empiriques les plus récentes, qui tentent de cartographier les zones et les structures cérébrales à l'origine d'une expérience donnée. Toutefois, l'étude montre l'inadéquation de descriptions purement instrumentales et indique la nécessité d'appréhender la nature du passage du niveau neuronal au niveau mental pour expliquer le phénomène de la conscience. Il faut donc étudier les complexes mécanismes 
de réalisation de la conscience, qui ont comme fondement la temporalité immanente, le flux de vie au sein duquel surgit la conscience originaire du temps. Pour ce faire, il devient nécessaire d'atteindre un point d'observation privilégié, capable d'inclure conceptuellement les diverses facettes de la concrétisation de la conscience. L'auteur affirme la nécessité d'une recherche transdisciplinaire, conjuguant philosophie, psychologie et neurophysiologie.

Mots clés: Conscience, temporalité, expérience temporelle, phénoménologie de la temporalité

(Consciousness of temporality and the temporality of consciousness)

The time-consciousness relationship has been neglected by scientific research. Temporality is the origin and structure of consciousness. Therefore, temporal experience cannot be effectively approached simply through empirical research, since transdisciplinary conceptual investigations are needed. This article presents considerations on the most relevant investigations in the area, beginning with Husserl's phenomenological considerations on the structure and consciousness of time, and moving ahead to the most recent empirical studies aimed at mapping brain structures and areas related to certain experiences. However, the study shows up the inadequacy of mere instrumental descriptions and points out the need to grasp the nature of the passage from the neural level to the mental level in order to explain the phenomenon of consciousness. It is therefore necessary to investigate the complex mechanisms involved in consciousness, the foundation of which is immanent temporality, the flow of life, where time-based consciousness emerges. For this, an adequate point of observation must be established that can conceptually encompass the various angles of the substantiation of consciousness. The author posits the need for transdisciplinary research, including at least philosophy, psychology and neurophysiology.

Key words: Consciousness, temporality, temporal experience, the phenomenology of temporality

Versão inicial recebida em abril de 2006

Versão aprovada para publicação em novembro de 2007

\section{Mauro Maldonato}

Professore Associato Università degli Studi della Basilicata (Potenza, Itália)

Via Nazario Sauro 85

85100 Potenza, Itália

e-mail: maldonato@unibas.it 